\title{
Burnout and Risk Factors for Arteriosclerotic Disease: Follow-up Study
}

\author{
Kazuyo Kitaoka-Higashiguchi ${ }^{1}$, Yuko Morikawa ${ }^{1}$, Katsuyuki Miura ${ }^{2}$, Masaru Sakurai ${ }^{1}$, \\ Masao IshizaKI ${ }^{3}$, Teruhiko KIDO ${ }^{4}$, Yuchi NARUSE ${ }^{5}$ and Hideaki NAKAGawA ${ }^{1}$
}

${ }^{1}$ Department of Public Health, Kanazawa Medical University, ${ }^{2}$ Department of Health Science, Shiga University of Medical Science, ${ }^{3}$ Department of Social and Environmental Medicine, Kanazawa Medical University, ${ }^{4}$ School of Health Sciences, Kanazawa University and ${ }^{5}$ School of Nursing, Toyama University, Japan

\begin{abstract}
Burnout and Risk Factors for Arteriosclerotic Disease: Follow-up Study: Kazuyo Kitaoka-Higashiguchi, et al. Department of Public Health, Kanazawa Medical University-Objectives: The purpose of this longitudinal study was to investigate the effects of burnout on risk factors for arteriosclerotic disease. Methods: Baseline data were collected from 442 male middle managers working for a manufacturing company in Japan. All participants had a physical health check-up and completed the Japanese Maslach Burnout Inventory-General Survey. We calculated the Japanese-specific cut-off points of the MBI-GS and applied "exhaustion +1 " criterion to define subjects as healthy or burnout at baseline. Follow-up measures were collected 4-5 yr later for 383 middle managers. Changes in the subjects' waist circumference, body weight, body mass index (BMI), blood pressure, total cholesterol, triglycerides, HDL cholesterol, LDL cholesterol, fasting blood sugar, fasting insulin, HOMA$\mathrm{R}$, and $\mathrm{HbA1c}$ over a time period of 4 to $5 \mathrm{yr}$ were compared between the healthy and burnout groups. New cases of large waist circumference, high BMI, metabolic syndrome, hypertension, hypercholesterolemia, high triglycerides, low HDL cholesterol, high LDL cholesterol, and impaired fasting glucose were detected at follow-up. Results: Changes in waist circumference, body weight, and BMI were significantly greater in burned-out managers than in healthy managers. Furthermore, compared to other variables (age and health behaviors such as smoking), burnout was a significant explanatory variable. The odds ratio of the burnout group was 2.80 for
\end{abstract}

Received Jul 18, 2008; Accepted Jan 4, 2009

Published online in J-STAGE Feb 10, 2009

Correspondence to: K. Kitaoka-Higashiguchi, Department of Public Health, Kanazawa Medical University, Daigaku 1-1, Uchinada, Kahoku-gun, Ishikawa 920-0293, Japan

(e-mail: kitaoka@kanazawa-med.ac.jp) hypercholesterolemia with statistical significance after adjusting for age. After adjusting for age, health behaviors, and baseline total cholesterol, the results were similar. Conclusions: Burnout, which results from prolonged exposure to chronic work stress, may be associated with risk factors for arteriosclerotic disease.

(J Occup Health 2009; 51: 123-131)

Key words: Arteriosclerotic disease, Burnout, Longitudinal study, Maslach Burnout Inventory (MBI), Working population

Burnout is the result of prolonged exposure to chronic work stress with insufficient recovery ${ }^{1-5)}$. Maslach and Jackson $^{6,7)}$ provided an operational definition of burnout in terms of the demands of human service work and developed the primary measure of the burnout construct, the Maslach Burnout Inventory (MBI). Given the increasing interest in burnout within occupations that are not clearly people-oriented ${ }^{8)}$, the MBI-General Survey $(\mathrm{MBI}-\mathrm{GS})^{9)}$ was developed. In the MBI-GS, the three components of the burnout construct are conceptualized in slightly broader terms with respect to occupation, and not just to the personal relationships that may be part of the job. The three components are labeled exhaustion, cynicism, and diminished professional efficacy.

A large number of burnout studies have examined the correlates and the causes of burnout, but a few studies have focused on its attitudinal and organizational consequences and its negative impact on mental health. Moreover, there are scant data available on the impact that burnout has on physical health ${ }^{5,10,11)}$. A prospective cohort study dealing with job stress found that chronic work stress is an important risk factor for the development of metabolic syndrome ${ }^{12}$. This study provides evidence for the biological plausibility of a link between everyday life psychosocial stressors and heart disease. On the other 
hand, physical health problems that are more or less objectively diagnosed have been investigated with respect to burnout ${ }^{10,11,13-16)}$. Other studies have investigated the relationship between burnout and objectively diagnosed physical health problems. The relationships between burnout and indicators such as cholesterol and lipid peroxidation have been examined ${ }^{13,17,18)}$. Burnout has been found to be associated with cardiovascular disease (CVD) in a few studies ${ }^{19-23)}$. However, no definitive, longitudinal studies dealing with the relationship between burnout as assessed using the MBI and objectively diagnosed health problems have been published.

In the present longitudinal study, the effects of burnout on risk factors for arteriosclerotic disease were assessed.

\section{Subjects and Methods}

\section{Study population and data collection}

The study population included male middle managers working for a manufacturing company in Japan. The company has approximately 7,000 employees: upper managers, middle managers, and general employees. Middle managers predominantly manage clerical work and supervisory work in the manufacturing sections. The target company had three types of health examinations for employees: an annual health examination as mandated by law in Japan; a comprehensive health check-up program, involving a physical health examination, including laboratory tests, and a questionnaire concerning health behaviors and mental health held in the health care unit of the company; and intensive health examinations held in hospital. Middle managers were encouraged to participate in the health check-up program. The MBIGS was performed as part of the mental health examination in the health check-up program for middle managers at baseline in 2001.

The final study population for which all necessary data for this study were available included 442 men aged less than $55 \mathrm{yr}$ at baseline. Changes in the physical condition 4 to $5 \mathrm{yr}$ later were analyzed in relation to burnout. When we could not obtain enough data for subjects in 2005, because they had other types of health check-ups or other reasons, we used data obtained in 2006 to achieve a higher follow-up rate. Thus, in total, 383 male middle managers were followed up 4 to $5 \mathrm{yr}$ after baseline, and the followup rate was $86.7 \%$.

The following risk factors for arteriosclerotic disease were assessed: waist circumference, body weight, body mass index (BMI), blood pressure, total cholesterol, triglycerides, high density lipoprotein (HDL) cholesterol, low density lipoprotein (LDL) cholesterol, fasting blood sugar, fasting insulin, HOMA-R (see below), and HbA1c. HOMA-R was calculated on the basis of fasting blood sugar and insulin: fasting blood sugar $(\mathrm{mg} / \mathrm{d} l) \times$ fasting insulin $(\mu \mathrm{U} / \mathrm{m} l) / 405$. Waist circumference was measured to the nearest $0.5 \mathrm{~cm}$ above the iliac crests and below the lowest rib margin at minimal respiration in a standing position. Body weight was measured in light clothing without shoes using a standard scale and height was measured to the nearest $0.1 \mathrm{~cm}$ without socks using a stadiometer. Blood pressure was determined with a mercury sphygmomanometer in a sitting position after rest for 5 min. Fasting blood samples were taken from the subjects at least 10 hours after their last meal. Laboratory tests were performed by a laboratory test center. Total cholesterol, triglycerides, and LDL cholesterol were measured by enzyme assay. HDL cholesterol was measured by the direct method. The hexokinaze method, chemiluminescence immunoassay, and latex agglutination method were used respectively, to measure fasting blood sugar, fasting insulin, and HbA1c.

Alcohol consumption, smoking, and physical activity were assessed using a questionnaire. Alcohol consumption was classified into three categories: almost no drinks, drinks 1-4 days per week, and drinks more than 5 days per week. Smoking was categorized as either a current smoker or not a current smoker. Physical activity was categorized as either participating in at least one exercise session per week or not.

\section{Burnout}

Burnout was assessed using the Japanese version of the MBI-GS ${ }^{24,25)}$. The Japanese MBI-GS is a 16-item measure containing five items dealing with exhaustion, five dealing with cynicism, and six dealing with professional efficacy. The original version responses were used: never, a few times a year, once a month, a few times a month, once a week, a few times a week, and everyday. All 16 items of the MBI-GS are scored ranging from " 0 " (never) to " 6 " (everyday), and the total scores for each subscale were divided by the number of items for the subscale.

Except for studies done in The Netherlands ${ }^{26)}$ and Sweden ${ }^{27)}$, there are no clinically valid cut-off points available for the MBI that allow differentiation between levels of burnout. The MBI test manual presents numerical cut-off points based on arbitrary statistical norms ${ }^{9}$. The test authors divided the normative sample into tertiles, but since this was done using a Canadian sample ${ }^{28)}$, the classification in the manual cannot be applied to workers in Japan; only nation-specific cut-off points should be used ${ }^{29,30)}$. For this reason, cut-off points were determined based on data obtained from the many different studies ${ }^{24,25,31-35)}$ conducted by us so far, including the MBI-GS data obtained at the baseline of the present study. Overall, there were 5,621 samples (3,042 males, 2,515 females, 64 unknown). Although the average age differed among the studies, the overall average age was $37.8 \mathrm{yr}$ ( \pm S.D. 11.6), and age groups ranging from the 20 s through the 60 s were included. Subjects' occupations 
included company employees (new employees, general employees, and managers), civil servants, medical doctors (medical doctors and residents), clinical nurses, and teachers. The Japanese data were divided into tertiles. For exhaustion and cynicism, the cut-off point was set between the upper third and the lower two thirds, and for professional efficacy, the cut-off point was set between the higher two thirds and the lower third. Thus, for exhaustion, the cut-off point was 3.60 or higher; for cynicism, the cut-off point was 2.20 or higher; and for professional efficacy, the cut-off point was 1.83 or lower. It is commonly held that, in the process of burnout, exhaustion comes first, followed by cynicism and diminished professional efficacy ${ }^{3}$. In line with this idea, subjects with intense exhaustion and either a high level of cynicism or a low level of professional efficacy, or both, were considered to have burned out. In short, the "exhaustion + 1" criterion recommended by Brenninkmeijer and VanYperen ${ }^{36)}$ was applied. In accordance with this criterion, the baseline MBI-GS scale scores were divided into a healthy group and a burnout group. As a result, 46 subjects were categorized as belonging to the burnout group, and the remaining 337 as belonging to the healthy group. The average age was $48.3 \mathrm{yr}( \pm$ S.D. 4.6) for the healthy group and $47.3 \mathrm{yr}( \pm$ S.D. 4.8) for the burnout group; the difference was not statistically significant.

\section{Statistical methods}

First, health behaviors of the healthy group and the burnout group at baseline and follow-up were compared using the Chi-square test. Means of subjects' waist circumference, body weight, BMI, blood pressure, total cholesterol, triglycerides, HDL cholesterol, LDL cholesterol, fasting blood sugar, fasting insulin, HOMA$\mathrm{R}$, and $\mathrm{HbA} 1 \mathrm{c}$ at baseline were compared between the healthy and burnout groups using the $t$-test. The distribution of triglycerides, fasting blood sugar, fasting insulin, and HOMA-R was not normal, so a logarithmic transformation to normalize the distribution was applied.

Next, changes in the parameters over a time period of 4 to $5 \mathrm{yr}$ were compared between the two groups. In order to compare the averages, the $t$-test and analyses of covariance (ANCOVA) were performed. Since changes in all parameters were distributed normally, mean and standard deviation were used. The baseline values of the corresponding variables were adjusted as the covariates.

Furthermore, the relationship between burnout and changes of the parameters was evaluated. Multiple regression analyses were done to determine the effect of burnout on each variable, after adjusting for the other factors. The input variables were burnout ( $1=$ healthy, $2=$ burned out), age (continuous variable), alcohol consumption ( $1=$ almost no drinks, $2=$ drinks $1-4$ days per week, $3=$ drinks more than 5 days per week), smoking
( $1=$ a current smoker, $2=$ not a current smoker), and physical activity $(1=$ no exercise, $2=$ participating in at least one exercise session per week). Ordinal numbers were used to categorize alcohol consumption.

New cases of large waist circumference (waist circumference $\geq 85 \mathrm{~cm})$, high BMI $(\mathrm{BMI} \geq 25$ ), metabolic syndrome, hypertension (blood pressure $\geq 140 / 90 \mathrm{mmHg}$ ), hypercholesterolemia (total cholesterol $\geq 220 \mathrm{mg} / \mathrm{d} l$ ), high triglycerides (triglycerides $\geq 150 \mathrm{mg} / \mathrm{d} l$ ), low HDL cholesterol (HDL cholesterol $<40 \mathrm{mg} / \mathrm{d} l$ ), high LDL cholesterol (LDL cholesterol $\geq 140 \mathrm{mg} / \mathrm{d} l$ ), and impaired fasting glucose (fasting blood sugar $\geq 110 \mathrm{mg} / \mathrm{d} l$ ) were detected at follow-up. The definition of the Japanese Society of Internal Medicine ${ }^{37)}$ was used for metabolic syndrome. According to this definition, metabolic syndrome is defined as the presence of waist circumference larger than $85 \mathrm{~cm}$ in males and two or more risk factors: blood pressure $\geq 130 / 85 \mathrm{mmHg}$, fasting blood sugar $\geq 110 \mathrm{mg} / \mathrm{d} l$, triglycerides $\geq 150 \mathrm{mg} / \mathrm{d} l$ or HDL cholesterol $<40 \mathrm{mg} / \mathrm{d} l$. Those considered as new cases were subjects who fell short of the diagnostic criteria at baseline and either met the criteria at follow-up or were undergoing medical treatment. Multiple logistic regression analyses were carried out to evaluate the effects of burnout on the onset of those cases after adjusting for confounding factors. Two models were tested: model 1, with adjustment for age; model 2, with adjustment for age, health behaviors (alcohol consumption, smoking, physical activity), and baseline value of the corresponding variable.

Significance levels were set at $p<0.05$. All statistical analyses were performed using SPSS 15.0 software for Windows Vista.

\section{Ethics}

Ethical approval was obtained from the Kanazawa Medical University Epidemiological Research Ethics Committee.

\section{Results}

Table 1 shows the prevalence of habitual drinking, smoking, and exercise in the two groups; there were no differences between the groups at baseline and at followup. Additionally, there was no significant change in the prevalence of these habits between baseline and followup.

Table 2 compares the baseline risk factors for arteriosclerotic diseases between the healthy and burnout groups; there were no significant differences between the two groups.

Table 3 compares the changes in the risk factors at follow-up between the two groups. It shows both a simple comparison and the results of the co-variance analyses that used the baseline values of the corresponding variables as the covariates. 
Table 1. Health behaviors of the healthy group $(n=337)$ and the burnout group $(n=46)$ at baseline and follow-up

\begin{tabular}{|c|c|c|c|c|c|c|c|c|}
\hline \multirow{3}{*}{ Health behavior } & \multicolumn{4}{|c|}{ Baseline } & \multicolumn{4}{|c|}{ Follow-up } \\
\hline & \multicolumn{2}{|c|}{ Healthy } & \multicolumn{2}{|c|}{ Burnout } & \multicolumn{2}{|c|}{ Healthy } & \multicolumn{2}{|c|}{ Burnout } \\
\hline & $\mathrm{n}$ & $(\%)$ & $\mathrm{n}$ & $(\%)$ & $\mathrm{n}$ & $(\%)$ & $\mathrm{n}$ & $(\%)$ \\
\hline \multicolumn{9}{|l|}{ Alcohol consumption } \\
\hline Almost no drinks & 60 & $(17.8)$ & 8 & $(17.4)$ & 62 & $(18.4)$ & 10 & $(21.7)$ \\
\hline Drinks 1-4 days per week & 78 & $(23.1)$ & 10 & $(21.7)$ & 65 & $(19.3)$ & 9 & $(19.6)$ \\
\hline Drinks more than 5 days per week & 199 & $(59.1)$ & 28 & $(60.9)$ & 210 & $(62.3)$ & 27 & $(58.7)$ \\
\hline \multicolumn{9}{|l|}{ Smoking } \\
\hline A current smoker & 169 & $(50.1)$ & 22 & $(47.8)$ & 142 & $(42.1)$ & 21 & $(45.7)$ \\
\hline Not a current smoker & 168 & $(49.9)$ & 24 & $(52.2)$ & 195 & $(57.9)$ & 25 & $(54.3)$ \\
\hline \multicolumn{9}{|l|}{ Physical activity } \\
\hline No exercise & 192 & $(57.0)$ & 29 & $(63.0)$ & 199 & $(59.1)$ & 29 & $(63.0)$ \\
\hline Exercise & 145 & $(43.0)$ & 17 & $(37.0)$ & 138 & $(40.9)$ & 17 & $(37.0)$ \\
\hline
\end{tabular}

Table 2. Means of risk factors for arteriosclerotic disease of the healthy group $(n=337)$ and the burnout group ( $n=46)$ at baseline

\begin{tabular}{|c|c|c|c|c|c|}
\hline \multirow{2}{*}{$\begin{array}{l}\text { Risk factors } \\
\text { Waist circumference }(\mathrm{cm})\end{array}$} & \multicolumn{2}{|c|}{ Healthy group } & \multicolumn{2}{|c|}{ Burnout group } & \multirow{2}{*}{$\frac{p \text { value }^{\mathrm{a}}}{0.43}$} \\
\hline & 83.3 & 7.5 & 82.4 & 7.7 & \\
\hline Body weight (kg) & 68.6 & 8.7 & 68.2 & 10.0 & 0.73 \\
\hline Body mass index $\left(\mathrm{kg} / \mathrm{m}^{2}\right)$ & 23.9 & 2.7 & 23.5 & 2.8 & 0.39 \\
\hline Systolic blood pressure (mmHg) & 121.6 & 14.3 & 122.1 & 12.0 & 0.84 \\
\hline Diastolic blood pressure (mmHg) & 76.2 & 10.2 & 75.8 & 9.0 & 0.80 \\
\hline Total cholesterol (mg/d $l)$ & 202.4 & 30.8 & 204.9 & 30.9 & 0.61 \\
\hline Triglycerides $(\mathrm{mg} / \mathrm{d} l)$ & 114.8 & $(67.5-195.2)$ & 107.2 & $(56.4-203.7)$ & 0.49 \\
\hline HDL cholesterol (mg/d $l)$ & 51.1 & 13.0 & 52.7 & 11.9 & 0.43 \\
\hline LDL cholesterol (mg/d $l$ ) & 124.4 & 30.9 & 124.6 & 36.8 & 0.98 \\
\hline Fasting blood sugar (mg/d $l$ ) & 93.3 & $(77.8-112.0)$ & 93.3 & $(77.8-112.0)$ & 0.71 \\
\hline Fasting insulin $(\mu \mathrm{U} / \mathrm{m} l)$ & 4.8 & $(2.8-8.2)$ & 4.7 & $(2.8-8.0)$ & 0.76 \\
\hline HOMA-R & 1.1 & $(0.7-1.9)$ & 1.1 & $(0.6-2.0)$ & 0.70 \\
\hline HbA1c (\%) & 5.1 & 0.5 & 5.1 & 0.6 & 0.82 \\
\hline
\end{tabular}

a: $t$-test. Data are mean and SD (standard deviation). Triglycerides, fasting blood sugar, fasting insulin, and HOMA-R are changed from logarithmic value and numbers in parentheses of them are range.

There were significant differences between the healthy and burnout groups in regard to waist circumference, body weight, and BMI. While the healthy group had an estimated average change of $0.6 \mathrm{~cm}$ in waist circumference, the average change in the burnout group was $2.4 \mathrm{~cm}$, which was significantly greater than that of the healthy group. The estimated average change in body weight was $-0.4 \mathrm{~kg}$ in the healthy group and $1.2 \mathrm{~kg}$ in the burnout group. While the healthy group generally lost weight, the burnout group gained weight; the difference between the groups was significant. The estimated average change in BMI was -0.1 for the healthy group and 0.4 for the burnout group. As with body weight, the BMI of the healthy group decreased while that of the burnout group increased; again, the difference between the groups was significant.

There was no significant difference in systolic blood pressure or diastolic blood pressure between the healthy group and the burnout group.

While the healthy group had an estimated average change of $6.6 \mathrm{mg} / \mathrm{d} l$ on total cholesterol, the estimated average change $(12.8 \mathrm{mg} / \mathrm{d} l)$ tended to be larger in the burnout group; but it was not statistically significant. A significant difference in HDL and LDL cholesterol as well as triglycerides was not found between the two groups.

No significant difference between the healthy and burnout groups was found regarding fasting blood sugar, fasting insulin, HOMA-R, and HbA1c.

Using the variables (waist circumference, body weight, 
Table 3. Changes in risk factors for arteriosclerotic disease at follow-up of the healthy group ( $\mathrm{n}=337)$ and the burnout group $(n=46)$

\begin{tabular}{|c|c|c|c|c|c|c|c|c|c|c|}
\hline \multirow[t]{2}{*}{ Risk factors } & \multicolumn{2}{|c|}{ Healthy group } & \multicolumn{2}{|c|}{ Burnout group } & \multicolumn{3}{|c|}{ Healthy group } & \multicolumn{2}{|c|}{ Burnout group } & \multirow[b]{2}{*}{$p$ value ${ }^{\mathrm{b}}$} \\
\hline & Mean & SD & Mean & SD & $p$ value ${ }^{a}$ & mean & SE & mean & $\mathrm{SE}$ & \\
\hline Waist circumference $(\mathrm{cm})$ & 0.5 & 4.5 & 2.6 & 5.9 & 0.01 & 0.6 & 0.2 & 2.4 & 0.7 & 0.01 \\
\hline Body weight (kg) & -0.4 & 3.9 & 1.3 & 6.6 & 0.01 & -0.4 & 0.2 & 1.2 & 0.6 & 0.01 \\
\hline Body mass index $\left(\mathrm{kg} / \mathrm{m}^{2}\right)$ & -0.1 & 1.3 & 0.4 & 2.2 & 0.01 & -0.1 & 0.1 & 0.4 & 0.2 & 0.02 \\
\hline Systolic blood pressure (mmHg) & 1.9 & 13.4 & 2.1 & 16.7 & 0.94 & 1.9 & 0.7 & 2.2 & 1.9 & 0.89 \\
\hline Diastolic blood pressure $(\mathrm{mmHg})$ & 5.1 & 9.6 & 6.9 & 12.0 & 0.25 & 5.1 & 0.5 & 6.8 & 1.4 & 0.25 \\
\hline Total cholesterol $(\mathrm{mg} / \mathrm{d} l)$ & 6.7 & 22.0 & 12.3 & 27.3 & 0.12 & 6.6 & 1.2 & 12.8 & 3.2 & 0.07 \\
\hline Triglycerides $(\mathrm{mg} / \mathrm{d} l)$ & 1.1 & 95.0 & 11.7 & 182.3 & 0.54 & 0.8 & 5.4 & 13.1 & 14.6 & 0.43 \\
\hline HDL cholesterol $(\mathrm{mg} / \mathrm{d} l)$ & 5.6 & 9.2 & 4.7 & 9.2 & 0.52 & 5.6 & 0.5 & 4.9 & 1.3 & 0.61 \\
\hline LDL cholesterol (mg/d $l)$ & 0.9 & 23.2 & 5.3 & 31.7 & 0.25 & 0.9 & 1.2 & 5.3 & 3.3 & 0.21 \\
\hline Fasting blood sugar $(\mathrm{mg} / \mathrm{d} l)$ & 4.4 & 17.6 & 2.9 & 7.3 & 0.58 & 4.4 & 0.9 & 2.7 & 2.3 & 0.48 \\
\hline Fasting insulin $(\mu \mathrm{U} / \mathrm{m} l)$ & -1.0 & 3.9 & -0.7 & 2.8 & 0.59 & -1.0 & 0.2 & -0.8 & 0.5 & 0.71 \\
\hline HOMA-R & -0.1 & 1.1 & -0.1 & 0.7 & 0.98 & -0.1 & 0.1 & -0.2 & 0.2 & 0.94 \\
\hline HbA1c (\%) & 0.1 & 0.5 & 0.1 & 0.3 & 0.44 & 0.1 & 0.1 & 0.1 & 0.1 & 0.46 \\
\hline
\end{tabular}

a: $t$-test. b: Co-variance analyses adjusted for baseline value of the corresponding variable. SD indicates standard deviation. SE indicates standard error.

Table 4. Summary of multiple regression analyses of changes in waist circumference, body weight, BMI on explanatory variables of age, health behaviors, and burnout

\begin{tabular}{|c|c|c|c|c|c|c|c|c|c|}
\hline \multirow[b]{2}{*}{ Variables } & \multicolumn{3}{|c|}{ Waist circumference } & \multicolumn{3}{|c|}{ Body weight } & \multicolumn{3}{|c|}{ BMI } \\
\hline & B & SE & $p$ value & B & SE & $p$ value & $\mathrm{B}$ & SE & $p$ value \\
\hline Burnout & 1.93 & 0.74 & $<0.01$ & 1.67 & 0.68 & 0.01 & 0.54 & 0.22 & 0.01 \\
\hline Age & -0.13 & 0.05 & 0.01 & -0.09 & 0.05 & 0.07 & -0.02 & 0.02 & 0.14 \\
\hline Alcohol consumption & 0.09 & 0.31 & 0.76 & -0.03 & 0.29 & 0.93 & 0.02 & 0.09 & 0.86 \\
\hline Smoking & -0.41 & 0.48 & 0.40 & -0.25 & 0.44 & 0.57 & -0.07 & 0.14 & 0.63 \\
\hline Physical activity & -0.03 & 0.49 & 0.94 & -0.02 & 0.45 & 0.97 & -0.02 & 0.14 & 0.91 \\
\hline
\end{tabular}

Burnout: $1=$ healthy, $2=$ burned out. Age: continuous variable. Alcohol consumption: $1=$ almost no drinks, $2=$ drinks $1-4$ days per week, $3=$ drinks more than 5 days per week. Smoking: $1=$ a current smoker, $2=$ not a current smoker. Physical activity: $1=$ no exercise, $2=$ exercise. BMI indicates Body Mass Index. B indicates unstandardized coefficients. SE indicates standard error.

and BMI) that showed significant differences between the healthy and burnout groups, multiple regression analyses were performed. In all cases, burnout was a significant explanatory variable (Table 4).

Table 5 shows that odds ratios of the burnout group compared with the healthy group for the onsets of large waist circumference, high BMI, metabolic syndrome, hypertension, hypercholesterolemia, high triglycerides, low HDL cholesterol, high LDL cholesterol, and impaired fasting glucose. For large waist circumference, high BMI, metabolic syndrome, hypertension, high triglycerides, and impaired fasting glucose, the odds ratios of the burnout group were not high. The odds ratio of the burnout group was 2.80 for hypercholesterolemia with statistical significance after adjusting for age (model 1). After adjusting for age, health behaviors, and baseline total cholesterol (model 2), the results were similar. However, there was no significantly high odds ratio for low HDL cholesterol or high LDL cholesterol.

\section{Discussion}

This is the first longitudinal study of the effects of burnout on risk factors for arteriosclerotic disease. Burnout was measured using the Japanese version of the MBI-GS ${ }^{24,25)}$. Japanese-specific cut-off points of the MBI-GS were used and the "exhaustion +1 " criterion recommended by Brenninkmeijer and VanYperen ${ }^{36}$ was applied to classify Japanese subjects into two groups at 
Table 5. Odds ratios of the burnout group compared with the healthy group for onset of large waist circumference, high BMI, metabolic syndrome, hypertension, hypercholesterolemia, high triglycerides, low HDL cholesterol, High LDL cholesterol, and impaired fasting glucose

\begin{tabular}{|c|c|c|c|c|c|c|}
\hline \multicolumn{3}{|c|}{ Risk factors for arteriosclerotic disease } & \multicolumn{4}{|c|}{ Odds ratio $(95 \% \mathrm{CI})$} \\
\hline & Subjects a & No. of cases & Model 1 & $p$ value & Model 2 & $p$ value \\
\hline \multicolumn{7}{|c|}{ Large waist circumference (waist circumference $\geq 85 \mathrm{~cm}$ ) } \\
\hline Healthy group & 198 & 41 & 1 & & 1 & \\
\hline Burnout group & 28 & 7 & $1.28(0.44-3.78)$ & 0.65 & $1.46(0.49-4.38)$ & 0.50 \\
\hline \multicolumn{7}{|c|}{ High BMI (BMI $\geq 25)$} \\
\hline Healthy group & 224 & 19 & 1 & & 1 & \\
\hline Burnout group & 32 & 4 & $2.37(0.64-8.75)$ & 0.20 & $1.97(0.49-7.92)$ & 0.34 \\
\hline \multicolumn{7}{|c|}{ Metabolic syndrome b } \\
\hline Healthy group & 306 & 20 & 1 & & 1 & \\
\hline Burnout group & 42 & 3 & $1.14(0.32-4.03)$ & 0.84 & $1.17(0.33-4.15)$ & 0.81 \\
\hline \multicolumn{7}{|c|}{ Hypertension (blood pressure $\geq 140 / 90 \mathrm{mmHg}$ ) } \\
\hline Healthy group & 295 & 46 & 1 & & 1 & \\
\hline Burnout group & 44 & 6 & $0.62(0.23-1.66)$ & 0.34 & $0.67(0.25-1.77)$ & 0.41 \\
\hline \multicolumn{7}{|c|}{ Hypercholesterolemia (total cholesterol $\geq 220 \mathrm{mg} / \mathrm{d} l$ ) } \\
\hline Healthy group & 242 & 52 & 1 & & 1 & \\
\hline Burnout group & 34 & 15 & $2.80(1.23-6.39)$ & 0.01 & $2.78(1.20-6.46)$ & 0.02 \\
\hline \multicolumn{7}{|c|}{ High triglycerides (triglycerides $\geq 150 \mathrm{mg} / \mathrm{d} l$ ) } \\
\hline Healthy group & 241 & 38 & 1 & & 1 & \\
\hline Burnout group & 35 & 6 & $1.21(0.45-3.29)$ & 0.71 & $1.19(0.43-3.30)$ & 0.74 \\
\hline \multicolumn{7}{|c|}{ Low HDL cholesterol (HDL cholesterol <40 mg/d $l$ ) } \\
\hline Healthy group & 279 & 9 & 1 & & 1 & \\
\hline Burnout group & 39 & 1 & $0.95(0.11-0.79)$ & 0.96 & $0.83(0.09-7.50)$ & 0.87 \\
\hline \multicolumn{7}{|c|}{ High LDL cholesterol (LDL cholesterol $\geq 140 \mathrm{mg} / \mathrm{d} l$ ) } \\
\hline Healthy group & 243 & 39 & 1 & & 1 & \\
\hline Burnout group & 32 & 7 & $1.28(0.17-3.48)$ & 0.62 & $1.34(0.49-3.69)$ & 0.57 \\
\hline \multicolumn{7}{|c|}{ Impaired fasting glucose (fasting blood sugar $\geq 110 \mathrm{mg} / \mathrm{d} l$ ) } \\
\hline Healthy group & 307 & 34 & 1 & & 1 & \\
\hline Burnout group & 43 & 2 & $0.62(0.13-2.87)$ & 0.54 & $0.58(0.12-2.71)$ & 0.49 \\
\hline
\end{tabular}

a: Number of those who fell short of the diagnostic criteria at baseline. b: The presence of waist circumference $\geq 85 \mathrm{~cm}$, and two or more risk factors: blood pressure $\geq 130 / 85 \mathrm{mmHg}$, fasting blood sugar $\geq 110 \mathrm{mg} / \mathrm{d} l$, triglycerides $\geq 150 \mathrm{mg} / \mathrm{d} l$ or HDL cholesterol $<40$ $\mathrm{mg} / \mathrm{d} l$. Model 1: Adjusted for age. Model 2: Adjusted for age, health behaviors (alcohol consumption, smoking, physical activity), and baseline value of the corresponding variable. BMI indicates Body Mass Index.

baseline: a healthy group and a burnout group.

Changes in the values of risk factors for arteriosclerotic disease from baseline to follow-up were compared between the healthy group and the burnout group. Compared to healthy male middle managers, burned out managers had significant increases in their waist circumference, body weight, and BMI at the time of follow-up, 4 to 5 yr later. It is important to note that the associations identified in this study were independent of other risk factors for arteriosclerotic disease, such as age, alcohol consumption, smoking, and physical activity. Some studies have found an association between high job strain and increased $\mathrm{BMI}^{38,39}$. Others have reported no associations between these psychosocial characteristics of the work environment and $\mathrm{BMI}^{40-43)}$. In some samples, high job strain was associated with a lower $\mathrm{BMI}^{44,45)}$. The associations of job strain and its components with BMI have been found to vary by gender, but not in a consistent manner ${ }^{46,47)}$. The mixed findings that have been reported with respect to work stress and obesity may reflect a failure to take into account the possibility that stress may cause some people to eat more, but others to eat less ${ }^{48,49)}$. Moreover, the design of those studies was mostly cross-sectional. The Whitehall 2 study of Brunner et al. ${ }^{50)}$ examined cumulative job strain as a predictor of obesity in a prospective 19-yr study. That study provided prospective evidence that chronic work stress predicts obesity. To the best of our knowledge, there is only one prospective study that has investigated the association between burnout and obesity ${ }^{51)}$, but it did 
not provide evidence that burnout predicts obesity. The present study provides the first prospective evidence that burnout predicts general and central obesity.

With respect to lipid metabolism disorders, the burned out group showed a larger increase of total cholesterol and a significantly higher risk for hypercholesterolemia, independent of the other factors (age, baseline total cholesterol, and health behaviors), compared with healthy managers. However, other metabolic indicators and blood pressure were not different between the two groups. Melamed et al. ${ }^{22)}$ examined the association between burnout and risk factors for cardiovascular disease (CVD). They found in a cross-sectional study that scores for burnout plus tension were significantly associated with cholesterol, triglycerides, and glucose levels, while scores for burnout plus listlessness were significantly associated with glucose and diastolic blood pressure levels. Shirom et $a l .{ }^{17)}$ also performed a follow-up study on the effects of burnout on cholesterol and triglyceride levels. They found that physical and emotional burnout were both positive predictors of the change of total cholesterol levels. Those results about total cholesterol were similar to our results. Nonetheless, they did not assess burnout using the MBI, which is almost universally accepted as the standard for assessing burnout. In fact, the MBI has been used in over $90 \%$ of the empirical publications dealing with burnout ${ }^{4}$. Instead, Melamed et al. and Shirom et al. used their own definition of burnout and their own scale, the Shirom-Melamed Burnout Measure (SMBM). Our results might be significant because the are based on the MBI for burnout measurement.

What kind of biological mechanism is behind the fact that burnout tended to be associated with a larger waist circumference, body weight, and BMI, as well as a higher incidence rate of hypercholesterolemia? Although the biological mechanisms remain unclear, Brunner and Marmot $^{52)}$, in the Whitehall 2 study, presented a hypothetical model of the biological mechanism at work between job strain and cardiovascular diseases. We use this model to consider the mechanism in question. The hypothalamic-pituitary-adrenal (HPA) axis may be involved due to a direct effect of burnout. Burnout that arises as a result of prolonged exposure to chronic job strain results in the body always being on the alert for another stressor. As a result, the HPA axis remains hyperactive and fat accumulates, which leads to lipid abnormalities and results in general obesity and central obesity. Moreover, this mechanism could lead to appetite stimulation. In addition to these direct effects, burnout may also have indirect effects. After leaving work, many people release their stress by eating and/or drinking alcoholic beverages. This style of coping could lead to the excessive intake of fat and sugar, which in turn could lead to weight gain and increase of cholesterol.

The present study had some limitations. First, at the time of follow-up, individuals suffering from burnout at baseline significantly increased their waist circumference, body weight, and BMI, and they had a higher incidence of hypercholesterolemia. However, among these subjects no significant difference was observed in any of the other factors. If the significant increase in the waist circumference and the body weight had been associated with a significant increase in triglycerides and LDL cholesterol levels, and a significant decline in HDL cholesterol levels, this would have made the study's results easier to interpret. In fact, such trends were observed, but they were not statistically significant, primarily because the study population was rather small and thus lacked statistical power. Furthermore, the follow-up study period was too short to properly explore the effects of burnout on physical health. Therefore, we should be mindful of the possibilities of the under estimation of the effects of burnout on those variables. Second, MBI-GS was not measured at the follow-up. Accordingly, we could not assess the changes of burnout level in the subjects at follow-up, 4 to 5 yr later. However, because burnout arises as a result of prolonged exposure to chronic job strain, burnout is characterized by its chronic nature. Hence, baseline evaluation of burnout level might predict health in the future. Third, since all of the middle managers were male, the results may not be generalizable to women. Finally, none of the study participants were on sick leave, which indicates that the sample employees with burnout were relatively healthy. The physiological correlates of more advanced burnout may therefore be different from those observed in the present study. Nonetheless, our study is still significant one because of the study design, a follow-up study with measurement of burnout using the standard scale, MBI.

In conclusion, burnout, which results from prolonged exposure to chronic work stress, may be associated with risk factors for arteriosclerotic disease.

Acknowledgments: This study was supported by Grants-in-Aid for Scientific Research of Japan (Grant No. 18592433).

\section{References}

1) Maslach C, Schaufeli WB, Leiter MP. Job burnout. Annu Rev Psychol 2001; 52: 397-422.

2) Mommersteeg P, Heijnen C, Verbraak M, Doornen L. A longitudinal study on cortisol and complaint reduction in burnout. Psychoneuroendocrinology 2006; 31: 793-804.

3) Schaufeli W, Buunk BP. Burnout-An overview of 25 years of research and theorizing-. In: Schabracq MJ, Winnubst JAM, Cooper CL, editors. The handbook of work and health psychology, 2nd ed. England: John Wiley \& Sons; 2003. p.383-425.

4) Schaufeli WB, Enzmann D. The burnout companion to study and research-A critical analysis-. London 
(UK): Taylor \& Francis; 1998. p.19-99.

5) Toker S, Shirom A, Shapira I, Berliner S, Melamed S. The association between burnout, depression, anxiety, and inflammation biomarkers-C-reactive protein and fibrinogen in men and women-. J Occup Health Psychol 2005; 10: 344-62.

6) Maslach C, Jackson SE. The measurement of experienced burnout. J Occup Behav 1981; 2: 99-113.

7) Maslach C, Jackson SE. Maslach Burnout Inventory Research Edition Manual. Palo Alto (CA): Consulting Psychologists Press; 1981.

8) Maslach C, Schaufeli WB. Historical and conceptual development of burnout. In: Schaufeli WB, Maslach C, Marek T, editors. Professional burnout. Philadelphia (PA): Taylor \& Francis; 1993. p.1-16.

9) Maslach C, Jackson SE, Leiter MP. Maslach Burnout Inventory Manual, 3rd ed. Palo Alto (CA): Consulting Psychologists Press; 1996.

10) Honkonen $T$, Ahola $K$, Pertovaara M, et al. The association between burnout and physical illness in the general population-Results from the Finnish Health 2000 Study—. J Psychosom Res 2006; 61: 59-66.

11) Mohren DC, Swaen GM, Kant IJ, van Amelsvoort LG, Borm PJ, Galama JM. Common infections and the role of burnout in a Dutch working population. J Psychosom Res 2003; 55: 201-8.

12) Chandola T, Brunner E, Marmot M. Chronic stress at work and the metabolic syndrome-Prospective study-. BMJ 2006; 332: 521-5.

13) Hendrix WH, Steel RP, Leap TL, Summers TP. Development of a stress-related health promotion model-Antecedents and organizational effectiveness outcomes-. J Soc Behav Personal 1991; 6: 141-62.

14) Corrigan PW, Holmes EP, Luchins D. Burnout and collegial support in state psychiatric hospital staff. J Clin Psychol 1995; 51: 703-10.

15) Bhagat RS, Allie SM, Ford DL. Coping with stressful life events-An empirical analysis-. In: Crandall R, Perrewe PL, editors. Occupational stress-A handbook-. Philadelphia (PA): Taylor \& Francis; 1995. p.93-112.

16) Landsbergis PA. Occupational stress among health care workers-A test of the job demands-control modelJ Organ Behav 1988; 9: 217-39.

17) Shirom A, Westman M, Shamai O, Carel RS. Effects of work overload and burnout on cholesterol and triglycerides levels-The moderating effects of employee reactivity among male and female employees-. J Occup Health Psychol 1997; 2: 27588.

18) Casado A, De Lucas N, López-Fernández E, Sánchez A, Jimenez JA. Lipid peroxidation, occupational stress and aging in workers of a prehospital emergency service. Eur J Emerg Med 2006; 13: 165-71.

19) Appels A. Vital exhaustion as a precursor of myocardial infarction. In: Maes S, Spielberger D, Defaves PB, Sarason IG, editors. Topics in health psychology. New York (NY): Wiley; 1988. p.31-5.

20) Appels A, Schouten E. Burnout as a risk factor for coronary heart disease. Behav Med 1991; 17: 53-9.
21) Hallman T, Thomsson H, Burell G, Lisspers J, Setterlind S. Stress, burnout and coping-Differences between women with coronary heart disease and healthy matched women-. J Health Psychol 2003; 8: 433-45.

22) Melamed S, Kushnir T, Shirom A. Burnout and risk factors for cardiovascular diseases. Behav Med 1992; 18: 53-60.

23) Räikkönen K, Lassila R, Keltikangas-Järvinen L, Hautanen A. Association of chronic stress with plasminogen activator inhibitor-1 in healthy middleaged men. Arteriosclerosis, Thrombosis \& Vascular Biology 1996; 16: 363-7.

24) Kitaoka-Higashiguchi K, Nakagawa H, Morikawa Y, et al. Construct validity of the Maslach Burnout Inventory-General Survey. Stress Health 2004; 20: 255-60.

25) Kitaoka-Higashiguchi K, Ogino K, Masuda S. Validation of Japanese research version of Maslach Burnout Inventory-General Survey. Jpn J Psychol 2004; 75: 415-9.

26) Van der Klink JJL, van Dijk FJH. Dutch practice guidelines for managing adjustment disorders in occupational and primary health care. Scand J Work Environ Health 2003; 29: 478-87.

27) Friberg T. Diagnosing burn-out-An anthropological study of a social concept in Sweden-, Ph D thesis. Lund (Sweden): Lund University; 2006.

28) Leiter MP, Schaufeli WB. Consistency of the burnout construct across occupations. Anxiety Stress Coping 1996; 9: 229-43.

29) Schaufeli WB, Van Dierendonck D. The construct validity of two burnout measures. J Organ Behav 1993; 14: 631-47.

30) Schaufeli WB, Van Dierendonck D. A cautionary note about the cross-national and clinical validity of cut-off points for the Maslach Burnout Inventory. Psychol Rep 1995; 76: 1083-90.

31) Kitaoka-Higashiguchi K. Causal relationship of burnout to medical accident among psychiatric nurses. J Jpn Acad Nur Sci 2005; 25: 31-40.

32) Kitaoka-Higashiguchi K, Tanimoto C, Hayasi M, et al. Burnout and job stressor among psychiatric nurses. Ishikawa J Nur 2004; 1: 7-12.

33) Maeno K, Kajiwara H, Kawamura A, Tanaka K, Kitaoka-Higashiguchi K, Nakahashi K. Post arrangement of hospital nurses-Comparison of stress between the expected group and unexpected groupHokuriku J Public Health 2006; 32: 82-5.

34) Ogino K, Kitaoka-Higashiguchi K, Masuda S. Burnout of school teachers. A Psychol Odyssey of JPA 2006; 70: 1326 .

35) Yoshino S, Sasahara S, Maeno T, et al. Relationship between mental health of Japanese residents and the quality of medical service. JPFNI 2007; 17: 3-11.

36) Brenninkmeijer V, VanYperen N. How to conduct research on burnout-Advantages and disadvantages of a unidimensional approach in burnout research-. Occup Environ Med 2003; 60 (Suppl 1): i16-i20.

37) The Japanese Society of Internal Medicine, 
Examination Committee of Criteria for 'Metabolic Syndrome' in Japan. Definition and diagnostic criteria for metabolic syndrome. J Jpn Society Internal Med 2005; 94: 794-809.

38) Hellerstedt WL, Jeffery RW. The association of job strain and health behaviors in men and women. Int $\mathrm{J}$ Epidemiol 1997; 26: 575-83.

39) Wamala SP, Wolk A, Orth-Gomer K. Determinants of obesity in relation to socioeconomic status among middle-aged Swedish women. Prev Med 1997; 26: 734-44.

40) Brisson C, Larocque B, Moisan J, Vezina M, Dagenais GR. Psychosocial factors at work, smoking, sedentary behavior, and body mass index-A prevalence study among 6995 white collar workers-. J Occup Environ Med 2000; 42: 40-6.

41) Reed DM, LaCroix AZ, Karasek RA, Miller D, MacLean CA. Occupational strain and the incidence of coronary heart disease. Am J Epidemiol 1989; 129: 495-502.

42) Jonsson D, Rosengren A, Dotevall A, Lappas G, Wilhelmsen L. Job control, job demands and social support at work in relation to cardiovascular risk factors in MONICA 1995, Goteborg. J Cardiovasc Risk 1999; 6: $379-85$.

43) Landsbergis PA, Schnall PL, Deitz DK, Warren K, Pickering TG, Schwartz JE. Job strain and health behaviors-Results of a prospective study-. Am J Health Promot 1998; 12: 237-45.

44) Theorell T, Ahlberg-Hulten G, Jodko M, Sigala F, de la Torre B. Influence of job strain and emotion on blood pressure in female hospital personnel during workhours. Scand J Work Environ Health 1993; 19: 313-8.
45) Amick III BC, Kawachi I, Coakley EH, Lerner D, Levine S, Colditz GA. Relationship of job strain and iso-strain to health status in a cohort of women in the United States. Scand J Work Environ Health 1998; 24 : 54-61.

46) Overgaard D, Gyntelberg F, Heitmann BL. Psychological work-load and body weight-Is there an association? A review of the literature-. Occup Med 2004; 54: 35-41.

47) Ostry AS, Radi S, Louie AM, LaMontagne AD. Psychosocial and other working conditions in relation to body mass index in a representative sample of Australian workers. BMC Public Health 2006; 6: 5361.

48) Epel E, Jimenez S, Brownell K, Stroud L, Stoney C, Niaura R. Are stress eaters at risk for the metabolic syndrome? Ann N Y Acad Sci 2004; 1032: 208-10.

49) Kuvimäki M, Head J, Ferrie JE, et al. Work stress, weight gain and weight loss-Evidence for bidirectional effects of job strain on body mass index in the Whitehall II study-. Int J Obesity 2006; 30: 982-7.

50) Brunner EJ, Chandola T, Marmot MG. Prospective effect of job strain on general and central obesity in the Whitehall II study. Am J Epidemiol 2007; 165: 82837.

51) Armon G, Shirom A, Berliner S, Shapira I, Melamed S. A prospective study of the association between obesity and burnout among apparently healthy men and women. J Occup Health Psychol 2008; 13: 43-57.

52) Brunner E, Marmot M. Social organization, stress, and health. In: Marmot M, Wilkinson RG, editors. Social determinants of health, 2nd ed. New York (NY): Oxford University Press; 2006. p.6-30. 